\title{
NeUropsicologia do TRANSTORNO DO PÂNICO: REVISÃO SISTEMÁTICA E ESTUDO COMPARATIVO
}

\author{
Marta Bolshaw Gomes Vieira
}

\begin{abstract}
A presente dissertação de tese aborda a temática avaliação neuropsicológica na interface da psicologia clínica e da psicopatologia. É composta por dois estudos: um teórico e outro empírico. O estudo teórico tem como objetivo revisar a literatura dos últimos dez anos com o propósito de se ter um conhecimento panorâmico sobre o assunto. $\mathrm{O}$ estudo empírico tem como objetivo testar hipótese sobre o funcionamento cognitivo no TP, ou seja, testar a hipótese de que existe um déficit na função executiva e/ou seus componentes nesta psicopatologia.
\end{abstract}

\section{BANCA:}

Jesus Landeira Fernandez (Orientador)

Antonio Egidio Nardi

Helenice Charchat Fichman

Rochele Paz Fonseca (Co-Orientador)

Data de defesa: 9/04/2010 